Article

\title{
Bacillus nematocida B16 Enhanced the Rhizosphere Colonization of Pochonia chlamydosporia ZK7 and Controlled the Efficacy of the Root-Knot Nematode Meloidogyne incognita
}

\author{
Tingting Bo ${ }^{1,2}$, Chuixu Kong ${ }^{1,2}$, Shunxing Zou ${ }^{1,2}$, Minghe Mo ${ }^{1,2}$ and Yajun Liu ${ }^{1,2, * \mathbb{C}}$ \\ 1 State Key Laboratory for Conservation and Utilization of Bio-Resources, Yunnan University, \\ Kunming 650032, China; BTT0627@163.com (T.B.); KCX2430@163.com (C.K.); qq420633716@126.com (S.Z.); \\ minghemo@163.com (M.M.) \\ 2 Key Laboratory for Southwest Microbial Diversity of the Ministry of Education, Yunnan University, \\ Kunming 650032, China \\ * Correspondence: lyj@ynu.edu.cn
}

Citation: Bo, T.; Kong, C.; Zou, S.; Mo, M.; Liu, Y. Bacillus nematocida B16 Enhanced the Rhizosphere

Colonization of Pochonia chlamydosporia ZK7 and Controlled the Efficacy of the Root-Knot Nematode Meloidogyne incognita. Microorganisms 2022, 10, 218. https://doi.org/10.3390/ microorganisms 10020218 Academic Editors: Attila L. Ádám and Lorant Király

Received: 8 December 2021 Accepted: 18 January 2022 Published: 20 January 2022 Publisher's Note: MDPI stays neutral with regard to jurisdictional claims in published maps and institutional affiliations.

Copyright: () 2022 by the authors Licensee MDPI, Basel, Switzerland. This article is an open access article distributed under the terms and conditions of the Creative Commons Attribution (CC BY) license (https:// creativecommons.org/licenses/by/ $4.0 /)$.

\begin{abstract}
Pochonia chlamydosporia is widely applied in many countries as a biocontrol fungus against parasitic nematodes in plants. In a field experiment, the combined use of Bacillus nematocida B16 increased the biocontrol efficiency of P. chlamydosporia ZK7 against Meloidogyne incognita. Further study indicated that the colonization of P. chlamydosporia ZK7 in the rhizosphere soil and the roots of tomatoes was significantly higher in the combined use group than in the control group. Gas chromatography was conducted to determine the effects of signaling substances. Five compounds, hexanal, (E)-2-hexenal, furfural, benzaldehyde, and 2-nonanone, were found to be highly altered in the volatile compounds produced in the soil under the combined application. The changes in benzaldehyde and 2-nonanone were the main factors that resulted in an increase in the colonization of fungi $P$. chlamydosporia ZK7 in the tomato roots. Furfural was the main volatile substance that affected the colonization of fungi P. chlamydosporia ZK7 in the soil. The combined use of $B$. nematocida B16 and P. chlamydosporia ZK7 altered the volatile ranges and resulted in increased colonization of biocontrol fungi and improved biocontrol efficiency against nematodes. This combined model could be used to promote the ability of biocontrol fungi to control root-knot nematodes.
\end{abstract}

Keywords: P. chlamydosporia ZK7; B. nematocida B16; Meloidogyne incognita; combination control; volatiles

\section{Introduction}

Root-knot nematodes are a rhizosphere pest and are estimated to cause more than USD 1.73 billion in annual crop loss [1]. These parasitic nematodes not only cause direct damage to plant roots but also encourage other plant pathogens, including fungi, bacteria, and viruses, to infect plant roots. Traditional methods of controlling root-knot nematodes mainly use chemical insecticides. However, large amounts of chemical nematicides not only cause serious environmental problems but also harm human health [2,3]. As a result, many chemical pesticides have been banned or restricted.

Pochonia chlamydosporia is widely applied in many countries as a biocontrol fungus against parasitic nematodes in plants [4]. Regarded as one of the most versatile biocontrol agents for nematodes, this antagonist has many desirable properties as a biocontrol fungus. Due to its saprophytic activity, this fungus can survive in the soil even in the absence of nematodes [5]. The primary mechanism of action is through hyphae that invade nematode eggs and female cysts for asexual reproduction and extend out of the body to produce conidia, which leads to the death of eggs and female cysts to help control root-knot nematodes [6]. Bacillus is a kind of biocontrol bacterium that is widely distributed in the rhizospheres of plants. It can produce spores that are resistant to stress and can colonize 
and reproduce well in the soil. Moreover, the volatiles produced by B. nematocida B16 have different effects, including inducing plant resistance and nematicide activity $[7,8]$. However, soil treated with a single biocontrol agent is easily affected by ecological factors, and biocontrol efficiency is often unstable [9]. It is of potential value to use virulence factors of various biocontrol bacteria and their interactions to increase the reliability of nematode biocontrol efficiency [10]. The development of biocontrol agents for nematodes with high efficiency and reliability is much needed.

Microbes interact with each other through chemical-signaling substances. Microbial volatiles have strong diffusion and are often regarded as chemical-signaling molecules in many life activities [11]. Cao [12] found that actinomycete, Aguyces allii 130935, had an $89 \%$ nematocidal activity against $M$. incognita after $8 \mathrm{~h}$ and significantly reduced the root galls. Sphingosine was isolated from Bacillus cereus S2. The semi-lethal concentration of sphingosine on $M$. incognita was $0.64 \mu \mathrm{g} / \mathrm{mL}$ [13]. Zhou found that B. megaterium Sneb207 inhibits the invasion and reproduction of Heterodera glycines by inducing systemic resistance [14]. Two macrocyclic trichothecenes, verrucarin A and roridin A, were isolated from Meloidogyne verrucaria. The median effective concentrations of verructin $\mathrm{A}$ and roridin A against M. incognita were $1.88 \mu \mathrm{g} / \mathrm{mL}$ and $1.50 \mu \mathrm{g} / \mathrm{mL}$, respectively [15]. S. jietaisiensis could prevent root-knot disease and promote plant growth [16]. Fungi and bacteria are two distinct types of microbes, but they live in close proximity in the same environment and they each recognize the signals that the other produces, causing changes in the expression of related genes and corresponding changes in their behaviors [17]. There have been many reports about the impact of the volatiles produced by bacteria on the growth of fungi. Streptomyces globisporus can inhibit the growth of the spore-germ tubes of Penicillium italicum and cause abnormal conidia and hyphal shapes [18]. The volatiles of $S$. coccidioides can change the internal structure of the hyphae and the spores of Botrytis cinerea. After treatment with volatiles, the hyphae undergo plasmolysis, the cell walls of the spores thicken, and the vacuoles significantly increase [19]. Hassan [20] found that the volatiles of Bacillus licheniformis 350-2 had a significant inhibitory effect on the growth, sporulation, and accumulation of the mycotoxins of Aspergillus flavus and Penicillium.

In previous studies, the combined use of $P$. chlamydosporia ZK7 and B. nematocida B16 significantly improved the control effect of $P$. chlamydosporia ZK7 on the root-knot nematode Meloidogyne incognita. However, as B. nematocida B16 did not show an obvious biocontrol efficiency, this result suggested that the addition of B. nematocida B16 influenced the efficiency of the nematode's colonization ability, which is one of the key biocontrol factors for nematodes under the control of P. chlamydosporia ZK7. Thus, the current study investigated changes in chemical-signaling volatiles that result from the combined use of bacteria and fungi in the colonization of P. chlamydosporia ZK7, thereby improving its biocontrol ability against nematodes.

\section{Materials and Methods}

\subsection{Preparation of Strains}

Both P. chlamydosporia ZK7 and B. nematocida B16 were provided and stored by the Culture Collection of the State Key Laboratory for Conservation and Utilization of BioResources in Yunnan. Activated P. chlamydosporia ZK7 was incubated in a triangle flask with $250 \mathrm{~mL}$ of potato-dextrose-broth (PDB) medium for $72 \mathrm{~h}$ to obtain a spore count of $10^{6} / \mathrm{mL}$. The P. chlamydosporia ZK7 fermentation broth was filtered with six layers of sterilized microscopic paper to remove the hyphae. The spores were counted using a hemocytometer, and the final concentration of spores was adjusted to $10^{4} / \mathrm{mL}$ and stored at $4{ }^{\circ} \mathrm{C}$. The bacterial cells were incubated in a triangular flask with $200 \mathrm{~mL}$ of nutrient-broth (NB) medium for $36 \mathrm{~h}$. The optical density of the sample measured at a wavelength of $600 \mathrm{~nm}$ (OD600) was 1.8-2.0, and the sample was stored at $4{ }^{\circ} \mathrm{C}$. 


\subsection{Preparation of Meloidogyne incognita and Tomato Seedlings}

Meloidogyne incognita eggs were isolated from the root knots of tomato plants cultivated in a greenhouse, and eggs were collected on the 45th day after inoculation. The tomato roots were washed with a large amount of egg suspension, placed in a $500 \mathrm{~mL}$ triangular flask with $200 \mathrm{~mL}$ of $1 \% \mathrm{NaClO}$, and shaken vigorously for $3 \mathrm{~min}$. The egg suspension was rinsed and collected in a 400-mesh sieve. The concentration was adjusted to 200 granules $/ \mathrm{mL}$, and the samples were stored at $4{ }^{\circ} \mathrm{C}$.

Tomato seeds (Zhong za No.9, produced by Vegetable and Flower Research Institute, Chinese Academy of Agricultural Sciences) were disinfected with $5 \% \mathrm{NaClO}$ for 5 min and washed 3-5 times with sterile water. The seeds were transferred to a $16 \mathrm{~cm}$ culture dish with a layer of filter paper and incubated at a constant temperature of $28^{\circ} \mathrm{C}$ for $3-4$ days. After germination, the seeds were transferred to a drift tray with the substrate, incubated in a light incubator for 21 days (temperature of $28{ }^{\circ} \mathrm{C}$ and $75 \%$ humidity), and prepared for use after 4-6 new leaves had grown.

\subsection{Field Experiments}

The field experiment was conducted in Tong Hai County, Yunnan Province. The fermentation broth of strain P. chlamydosporia ZK7 was mixed with the fermentation broth of strain B. nematocida B16 in different proportions (i.e., 1:7, 1:3, 1:2, P. chlamydosporia ZK7 alone, B. nematocida B16 alone). For each treatment, $100 \mathrm{~mL}$ of a mixture of bacterial supernatant and spore suspension was added to each plant. The positive control was $100 \mathrm{~mL}$ of $0.5 \%$ avermectin per plant. The negative control was a blank control wherein no agents were used. All agents were applied at the time of transplantation, with 15 tomato plants for each treatment, and each treatment was repeated 3 times and randomly arranged. The control effect of each treatment was calculated. After 30 and 60 days of tomato transplantation, five tomatoes were collected for each treatment, and the following parameters were measured: the plant height, which is the distance from the soil to the top of the plant, and the fresh weight of the aboveground parts of the plant, which was measured using a balance after uprooting the plants, washing the roots under tap water, and cutting off the underground part with scissors. At 30, 60, and 90 days after transplantation, 5 tomatoes from each treatment were selected to investigate the disease index and biocontrol efficiency according to the classification method [21]: 0, no galls; I, $1-24 \%$ of the root galled; II, $25-49 \%$ of the root galled; III, $50-74 \%$ of the root galled; IV, $75-99 \%$ of the root galled; and V, all the roots galled, wherein:

$$
\text { disease index }=\frac{\sum(\text { number of plants al all levels } \times \text { series })}{(\text { total number of plants surveyed } \times 5)} \times 100 \% ;
$$

biocontrol efficiency $(\%)=\frac{(\text { control disease index }- \text { treatment disease index })}{\text { control disease index }} \times 100 \%$.

\subsection{Germination of Fungal Spores of P. chlamydosporia ZK7}

The B. nematocida B16 supernatant was mixed with the P. chlamydosporia ZK7 fermentation broth at proportions of 1:1, 1:3, 1:5, 1:7, and 1:10 and incubated on a rotary shaker at $28{ }^{\circ} \mathrm{C}$ and $170 \mathrm{rpm}$. Nutrient-broth medium and P. chlamydosporia ZK7 fermentation broth were used as controls. The spores of each treatment and control were counted using a hemocytometer after $4 \mathrm{~h}, 8 \mathrm{~h}, 12 \mathrm{~h}$, and $24 \mathrm{~h}$, and each treatment was conducted in triplicate.

\subsection{Egg Hatching of Meloidogyne incognita}

Sterile water $(2 \mathrm{~mL})$ and $1 \mathrm{~mL}$ egg suspension were added to a sterilized culture dish with a diameter of $60 \mathrm{~mm}$, and then a $1 \mathrm{~mL}$ mixture of B. nematocida B16 supernatant and P. chlamydosporia ZK7 spore suspension (volume ratio: 1:7) was added. Sterile water was used as the control. The culture dishes were sealed with paraffin. Three replicates were performed for each treatment and control. The culture was placed in an incubator at $25^{\circ} \mathrm{C}$ 
for 7-8 d. The number of hatched nematodes was counted under an optical microscope $(10 \times 10)$, and the relative inhibition rate was calculated.

\subsection{Analysis of Volatiles by Gas Chromatography-Mass Spectrometry}

To detect volatiles in the soil sample, $3 \mathrm{~g}$ of the pot experiment soil and $3 \mathrm{~mL}$ of sterile deionized water were added to a $15 \mathrm{~mL}$ headspace sample bottle. The bottle was corked, sealed with parafilm, and balanced at $20-25^{\circ} \mathrm{C}$ for 5 days. The SAAB- $5731875 \mu \mathrm{m}$ CAR/PDMS SPEM fiber was inserted and exposed approximately $1.5 \mathrm{~cm}$ above the liquid and stirred at $65^{\circ} \mathrm{C}$ for $1 \mathrm{~h}$. After sample extraction, a needle was inserted into the sample inlet of the gas chromatography gasification chamber, the fiber head was gently pushed downward, and the high temperature and heat conditions of the gasification chamber were used to allow the substance to be analyzed for $1 \mathrm{~min}$ for detection and analysis. Volatile organic compounds (VOCs) were detected by gas chromatography-mass spectrometry (GC/MS) using an Agilent 7890 GC/5975 MSD instrument. The column temperature was initially held at $50{ }^{\circ} \mathrm{C}$ for $2 \mathrm{~min}$, raised to $180^{\circ} \mathrm{C}$ at a rate of $6^{\circ} \mathrm{C}$ per min, and then increased to $240{ }^{\circ} \mathrm{C}$ at $8{ }^{\circ} \mathrm{C}$ per min, with a final hold time of $10 \mathrm{~min}$. Helium at a linear velocity of $1.0 \mathrm{~mL} / \mathrm{min}$ was used as the carrier gas. Compounds were identified by comparing the mass spectra with synthetic compounds and database data (NIST111L).

\subsection{Real-Time Polymerase Chain Reaction of P. chlamydosporia ZK7}

Genomic DNA of P. chlamydosporia ZK7 was extracted [22], amplified, and purified by polymerase chain reaction (PCR) (Takara DNA Purification Recovery Kit). Specific primers, namely, Spc-F1 (5' CGTTTCCAGTACaAGA 3') and SPC-R2 (5' TCTTCCTCTCAGTTGCCG $\left.3^{\prime}\right)$, these being fragments derived from the VCP1 gene, were used, with a total length of $136 \mathrm{bp}$ [18]. The purified PCR product was connected and transformed into Escherichia coli DH $5 \alpha$-competent cells and coated on an LB-ampicillin (AMP) plate. Single bacterial colonies were selected for colony PCR, and the colonies corresponding to the band size (136 bp) were selected and inoculated into LB-AMP liquid medium. The bacterial liquid was sent to BGI (Beijing Genomics institution) for sequencing verification. After the colony PCR-sequencing results were verified, the plasmid was extracted with a high-purity plasmid small-amount preparation kit. The high-purity (OD260/OD280 $=1.8 \sim 2.0)$ positive clone plasmid to multiple dilutions $(10 \times \tilde{\mathrm{A}}-)$ was selected, and the final concentration was $4.3 \times 102,103,104,105,106,107$, and 108 . The standard curve was prepared by quantitative PCR after dilution of the standard substance. The HP Fungal DNA Kit (OMEGA) was used to extract the DNA of the fungus in the root and the P. chlamydosporia ZK7 genomic DNA was stored at $-20^{\circ} \mathrm{C}$. The P. chlamydosporia ZK7 genome DNA was extracted from the soil according to the instructions of the Soil DNA Kit (OMEGA). After the extraction was completed, the DNA was saved at $-20^{\circ} \mathrm{C}$ for later use. The reaction conditions and system were the same as those for the preparation of the P. chlamydosporia ZK7 standard curve; however, the template was replaced with soil DNA and root fungal DNA.

\subsection{Pot Experiments}

Hexanal, (E)-2-hexenal, furfural, benzaldehyde, and 2-nonanone were added to $100 \mathrm{~mL}$ of P. chlamydosporia ZK7 fermentation broth and fully stirred to the final concentrations of $200 \mathrm{ppm}, 400 \mathrm{ppm}$, and $800 \mathrm{ppm}$. The blank control consisted of $100 \mathrm{~mL}$ of P. chlamydosporia ZK7 fermentation broth. Fermentation broth was added to the potted soil, and tomato seedlings with consistent growth and no disease were selected and transplanted into pots. After 30 days of transplanting, $0.2 \mathrm{~g}$ root and $60 \mathrm{~g}$ soil samples were collected to detect the colonization of $P$. chlamydosporia ZK7. The DNA of the root fungi was extracted with an HP Fungal DNA Kit (OMEGA), and the extraction procedure of the P. chlamydosporia ZK7 genome in the soil was performed according to the instructions of the Soil DNA Kit (OMEGA). After the extraction was completed, the samples were stored at $-20{ }^{\circ} \mathrm{C}$. The reaction conditions and system were the same as those of the P. chlamydosporia ZK7 standard curve, and the templates were replaced by soil DNA and root fungal DNA, respectively. 
The experimental soil samples were evenly mixed according to the ratio of field soil-humus soil-vermiculite at 3:1:1, and tomato seedlings with 4-6 leaves, consistent growth, and no disease were transplanted into $15 \mathrm{~cm}$ diameter pots filled with mixed soil samples. Two treatments were designed according to the efficiency of the field experiments performed earlier. Fermentation broth $(100 \mathrm{~mL})$ of B. nematocida B16-P. chlamydosporia ZK7 $(1: 7, v / v)$ was added around the root, and $100 \mathrm{~mL}$ of fermentation broth $P$. chlamydosporia ZK7 was used as a control. Each treatment was arranged in 15 pots, and 3 replicates were performed. The biocontrol efficiency and colonization of P. chlamydosporia ZK7 were detected at $0,15,30,45$, and 60 days.

\subsection{Statistical Analysis}

For the different biocontrol efficiency indexes, e.g., germination of fungal spores and relative inhibition rates of eggs by $P$. chlamydosporia $\mathrm{ZK} 7$, the data are shown as the mean \pm standard deviation $(n \geq 3)$. Comparisons of significance were performed using oneway analysis of variance (ANOVA) and Tukey's multiple comparison test at $p<0.05$. All statistical tests were performed using GraphPad Prism 7 software.

\section{Results}

\subsection{Biocontrol Efficiency in the Field Experiment}

The biocontrol efficiency of the different proportions of the agents on the nematodes showed significant differences. The results showed that treatment 1 (B. nematocida B16-P. chlamydosporia ZK7 = 1:7) had the most significant effects, reaching $77.5 \%$ at 30 days, $62.6 \%$ at 60 days, and $44.7 \%$ at 90 days. The biocontrol efficiency of B. nematocida B16 combined with P. chlamydosporia ZK7 was $146.82 \%$ higher than that of fungus $P$. chlamydosporia ZK7 alone. Treatments 2, 3, and 5 showed no biocontrol efficiency, and the theoretical biocontrol efficiency was only $10.4 \%, 3.7 \%$, and $2.6 \%$ at 90 days. The biocontrol efficiency of $P$. chlamydosporia ZK7 alone was also poor, with values of $31.4 \%, 16.4 \%$, and $2.6 \%$ at 30,60 , and 90 days, respectively. In addition, the positive control avermectin showed stable effects, maintaining approximately $40 \%$ biocontrol efficiency for three months (Table 1). The effects of plant height and biocontrol on the nematodes were similar. The growth rate of treatment 1 was still the highest, reaching $60 \%$ and $47.9 \%$ at 30 and 60 days, respectively, while the growth rates of the positive control were $79.5 \%$ and $33.9 \%$, respectively. Treatment 1 had an obvious promoting effect on the ground weight of the tomato plants, and the growth rate reached $100 \%$ and $25 \%$ at 30 and 60 days, respectively, similar to that of the positive control (Table 2).

Table 1. Effect of different treatments on galls and biocontrol efficiency in roots of tomato (conducted in field experiments).

\begin{tabular}{|c|c|c|c|c|c|c|}
\hline \multirow[b]{2}{*}{ Treatment } & \multicolumn{2}{|c|}{30 Days } & \multicolumn{2}{|c|}{60 Days } & \multicolumn{2}{|c|}{90 Days } \\
\hline & Gall Index & $\begin{array}{c}\text { Biocontrol } \\
\text { Efficiency }(\%)\end{array}$ & Gall Index & $\begin{array}{c}\text { Biocontrol } \\
\text { Efficiency }(\%)\end{array}$ & Gall Index & $\begin{array}{c}\text { Biocontrol } \\
\text { Efficiency (\%) }\end{array}$ \\
\hline $1(1: 7)$ & $1.67 \pm 0.43^{* * *}$ & 77.5 & $2.78 \pm 0.68^{* * *}$ & 62.6 & $4.67 \pm 1.55^{* *}$ & 44.7 \\
\hline $2(1: 3)$ & $5.92 \pm 1.33$ & 20.2 & $7.25 \pm 1.45$ & 14.8 & $7.56 \pm 1.64$ & 10.4 \\
\hline $3(1: 2)$ & $6.27 \pm 1.73$ & 15.5 & $7.22 \pm 1.89$ & 13.7 & $8.13 \pm 1.26$ & 3.7 \\
\hline 4 (ZK7) & $5.09 \pm 0.25$ & 31.4 & $6.22 \pm 1.17$ & 16.4 & $8.22 \pm 0.77$ & 2.6 \\
\hline 5 (B16) & $7.00 \pm 1.39$ & 5.7 & $7.44 \pm 0.69$ & 8.7 & $8.22 \pm 0.51$ & 2.6 \\
\hline 6 (avermectin) & $4.42 \pm 0.94 *$ & 40.4 & $4.56 \pm 1.20 *$ & 33.9 & $5.11 \pm 0.69^{* *}$ & 39.5 \\
\hline 7 (control) & $7.42 \pm 1.46$ & - & $7.44 \pm 1.17$ & - & $8.44 \pm 0.38$ & - \\
\hline
\end{tabular}

The supernatant of B. nematocida B16 was mixed with the spore suspension of P. chlamydosporia ZK7 in ratios of 1:7, 1:3, and 1:2 $(v / v)$; control was sterile deionized water. Data are expressed as the average of three replicates \pm SD (standard deviation). ${ }^{*} p<0.05,{ }^{* *} p<0.01,{ }^{* * *} p<0.001$.

\subsection{Influences of B. nematocida B16 Supernatant on the Germination of Fungal Spores}

The mixture of B. nematocida B16 supernatant and P. chlamydosporia ZK7 spore suspension at 1:3 had little effect on the germination rate of the spores as compared to the 
nutrient-broth control. As compared to the blank control, the effects of the supernatant B. nematocida $\mathrm{B} 16$ at ratios of 1:5 and 1:10 on the spore germination rate of $P$. chlamydosporia ZK7 were not significantly different. However, at a ratio of $1: 1$, the germination of the fungal spores was lower than that of the control, which indicated that a high concentration of B. nematocida B16 supernatant could inhibit the spore germination of P. chlamydosporia ZK7 (Table 3).

Table 2. Effects of different treatments on plant height and fresh weight of tomato (conducted in field experiments).

\begin{tabular}{ccccc}
\hline \multirow{2}{*}{ Treatment } & \multicolumn{2}{c}{ 30 Days } & \multicolumn{2}{c}{ 60 Days } \\
\cline { 2 - 5 } & Plant Height & Fresh Weight & Plant Height & Fresh Weight \\
\hline $1(1: 7)$ & $31.80 \pm 4.00$ & $0.40 \pm 0.04^{* * *}$ & $107.25 \pm 16.14$ & $0.50 \pm 0.02^{* * *}$ \\
$2(1: 3)$ & $20.80 \pm 3.23$ & $0.25 \pm 0.03$ & $83.25 \pm 26.50$ & $0.58 \pm 0.01^{* * *}$ \\
$3(1: 2)$ & $29.13 \pm 7.73$ & $0.35 \pm 0.03^{* * *}$ & $82.42 \pm 22.20$ & $0.45 \pm 0.03$ \\
$4($ ZK7) & $21.87 \pm 5.14$ & $0.40 \pm 0.02^{* * *}$ & $95.75 \pm 34.07$ & $0.52 \pm 0.04^{* * *}$ \\
5 (B16) & $23.33 \pm 7.65$ & $0.25 \pm 0.02$ & $78.83 \pm 35.00$ & $0.38 \pm 0.01$ \\
6 (avermectin) & $35.67 \pm 4.21$ & $0.45 \pm 0.03^{* * *}$ & $97.08 \pm 15.62$ & $0.55 \pm 0.03^{* * *}$ \\
7 (control) & $19.87 \pm 5.12$ & $0.20 \pm 0.03$ & $72.50 \pm 18.11$ & $0.40 \pm 0.02$ \\
\hline
\end{tabular}

The supernatant of B. nematocida B16 was mixed with the spore suspension of P. chlamydosporia ZK7 in ratios of 1:7, 1:3, and 1:2 $(v / v)$; control was sterile deionized water. Data are expressed as the average of three replicates $\pm \mathrm{SD}$ (standard deviation). ${ }^{* * *} p<0.001$.

Table 3. Influences of B. nematocida B16 supernatant on germination of fungal spore.

\begin{tabular}{ccccc}
\hline \multirow{2}{*}{ Treatment } & \multicolumn{4}{c}{ Germination of Fungal Spore (\%) } \\
\cline { 2 - 5 } & $\mathbf{4} \mathbf{h}$ & $\mathbf{8 ~ h}$ & $\mathbf{1 2} \mathbf{~ h}$ & $\mathbf{2 4} \mathbf{~ h}$ \\
\hline $1: 1$ & $8.81 \pm 1.70^{* * *}$ & $33.78 \pm 2.05^{* * *}$ & $74.51 \pm 3.09^{* * *}$ & $78.07 \pm 2.49^{* *}$ \\
$1: 3$ & $23.58 \pm 1.25$ & $55.79 \pm 3.30$ & $82.42 \pm 1.25$ & $85.18 \pm 3.56$ \\
$1: 5$ & $30.54 \pm 4.71$ & $74.79 \pm 0.82$ & $85.56 \pm 3.74$ & $89.28 \pm 6.55$ \\
$1: 7$ & $41.93 \pm 8.58^{* *}$ & $83.16 \pm 1.63^{* * *}$ & $93.79 \pm 4.97^{*}$ & $95.08 \pm 2.83^{*}$ \\
$1: 10$ & $26.16 \pm 1.63$ & $71.72 \pm 3.09$ & $72.80 \pm 1.70$ & $86.87 \pm 2.49$ \\
ZK7 & $32.78 \pm 2.87$ & $66.32 \pm 2.16$ & $85.65 \pm 3.40$ & $92.88 \pm 4.19$ \\
NB & $22.79 \pm 1.89$ & $55.67 \pm 1.41$ & $85.86 \pm 2.05$ & $87.29 \pm 3.09$ \\
\hline
\end{tabular}

The supernatant of B. nematocida B16 was mixed with the spore suspension of P. chlamydosporia ZK7 in ratios of 1:1 1:3, 1:5, 1:7, and 1:10 $(v / v) ; Z K 7$ spore suspension was used as blank control; the mixture of NB medium and ZK7 spore suspension 1:3 was used as medium control (total volume: $4 \mathrm{~mL}$ ). Data are expressed as the average of three replicates $\pm \mathrm{SD}$ (standard deviation). ${ }^{*} p<0.05,{ }^{* *} p<0.01,{ }^{* * *} p<0.001$.

\subsection{Influences on Egg Infection of Meloidogyne incognita}

In the nematode egg infection experiments, the inhibition rate of B. nematocida B16 supernatant on the nematode eggs was only $21.14 \%$, and there was no significant difference between the mixed treatment and P. chlamydosporia ZK7 alone, which indicated that $B$. nematocida $B 16$ could not promote the infection rate of $P$. chlamydosporia $Z K 7$ on nematode eggs (Table 4).

Table 4. Influences of different treatments on eggs of $M$. incognita by ZK7.

\begin{tabular}{ccc}
\hline Treatment & Number of Hatching & Relative Inhibition Rate (\%) \\
\hline B16 & $134.14 \pm 11.00$ & 21.14 \\
ZK7 & $32.67 \pm 9.84$ & 79.28 \\
B16 + ZK7 & $81.75 \pm 11.83$ & 68.16 \\
Control & $157.67 \pm 11.12$ & -
\end{tabular}

"-": no data. B16 + ZK7: the supernatant of B. nematocida B16 was mixed with the spore suspension of P. chlamydosporia ZK7 in a ratio of $1: 7(v / v)$; control was sterile deionized water. Data are expressed as the average of three replicates $\pm S D$ (standard deviation). 


\subsection{Colonization of P. chlamydosporia ZKZ in the Pot Experiment}

In a separate experiment, the changes in P. chlamydosporia ZK7 colonization in the tomato rhizosphere soil gradually decreased in a dose-dependent manner and varied from compound to compound. The colonization of P. chlamydosporia ZK7 in the presence of B. nematocida $\mathrm{B} 16$ reached the maximum value at 30 days, which increased the colonization of fungus P. chlamydosporia ZK7 by $392.97 \%$. When B. nematocida B16 was mixed with P. chlamydosporia ZK7, the change in the colonization of fungus P. chlamydosporia ZK7 in the roots showed a gradually increasing trend to the maximum value and then a gradually decreasing trend, reaching a maximum value at 15 days. The colonization of $P$. chlamydosporia ZK7 in the roots increased by $168.17 \%$ in the mixed treatment as compared to that in the individual treatment (Figure 1).
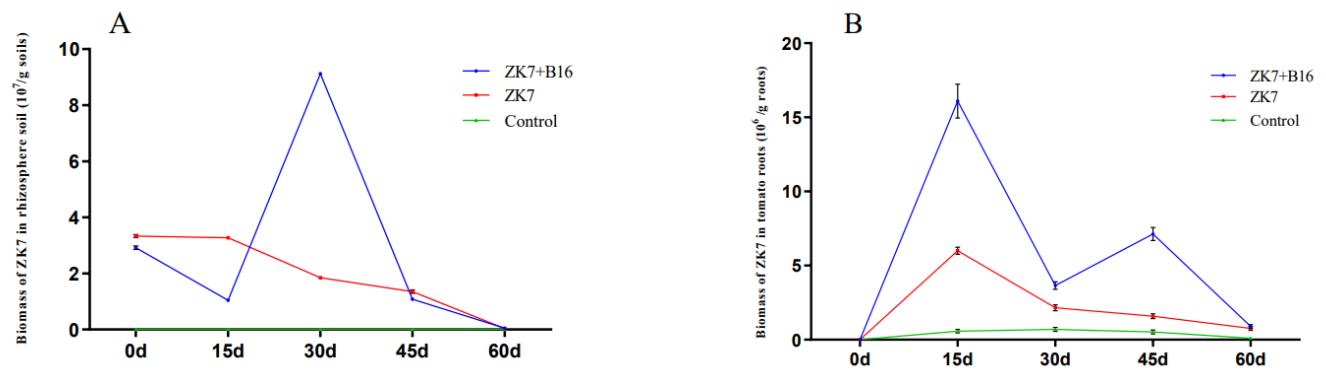

Figure 1. Changes in ZK7 colonization in root and rhizosphere soil of tomato in pot experiment. (A): Colonizations of P. chlamydosporia ZK7 in tomato rhizosphere soil; (B): colonizations of P. chlamydosporia ZK7 in tomato root. B16+ZK7: the supernatant of B. nematocida B16 was mixed with the spore suspension of $P$. chlamydosporia ZK7 in a ratio of 1:7 (total volume: $100 \mathrm{~mL}$ ). Data are expressed as the average of three replicates $\pm \mathrm{SD}$ (standard deviation).

\subsection{Biocontrol Efficiency in the Pot Experiment}

Compared with the blank control, the biocontrol efficiency of the P. chlamydosporia ZK7 and B. nematocida B16 combined treatment was maintained at approximately $50 \%$, and the efficiency of the positive control was $53 \%$ and $75 \%$ at 30 and 60 days, respectively. Conversely, the biocontrol efficiency of P. chlamydosporia ZK7 alone was only $23.1 \%$ and $33.4 \%$ at 30 and 60 days, respectively (Table 5). At 30 days, the plant height increased compared to that of the control, and the growth rate of P. chlamydosporia ZK7 combined with B. nematocida B16 reached 31.3\%. However, the effect of each treatment on the fresh weight of the aboveground parts was not significantly different. After 60 days, the plant height and fresh weight of the three treatments significantly increased, among which the growth rates of the P. chlamydosporia ZK7 and B. nematocida B16 combined treatments reached $71.7 \%$ and $42.3 \%$ for the height and fresh weight, respectively, and the growth rates of P. chlamydosporia ZK7 alone reached $9.8 \%$ and 19\%, respectively. The percentages of the positive controls were $7.8 \%$ and $29 \%$ for height and fresh weight, respectively (Table 6 ).

Table 5. Effect of different treatments on galls and biocontrol efficiency in roots of tomato (collected in pot experiments).

\begin{tabular}{ccccc}
\hline \multirow{2}{*}{ Treatment } & \multicolumn{2}{c}{ 30 Days } & \multicolumn{2}{c}{ 60 Days } \\
\cline { 2 - 5 } & Gall Index & $\begin{array}{c}\text { Biocontrol } \\
\text { Efficiency (\%) }\end{array}$ & Gall Index & $\begin{array}{c}\text { Biocontrol } \\
\text { Efficiency (\%) }\end{array}$ \\
\hline ZK7+B16 & $2.33 \pm 1.56$ & 46.2 & $2.00 \pm 0.67$ & 50 \\
ZK7 & $3.33 \pm 0.44$ & 23.1 & $2.67 \pm 0.44$ & 33.4 \\
$0.5 \%$ Avermectin & $2.00 \pm 1.33^{*}$ & 53.8 & $1.00 \pm 0.44 * *$ & 75 \\
Control & $4.33 \pm 0.44$ & - & $4.00 \pm 1.33$ & - \\
\hline \hline
\end{tabular}

"-":no data. ZK7+B16: B. nematocida B16 fermentation broth and P. chlamydosporia ZK7 fermentation broth were evenly mixed in a ratio of 1:7 (total volume: $100 \mathrm{~mL}$ ); control was sterile deionized water. Data are expressed as the average of three replicates $\pm \mathrm{SD}$ (standard deviation). ${ }^{*} p<0.05,{ }^{* *} p<0.01$. 
Table 6. Effects of different treatments on plant height and fresh weight of tomato (collected in pot experiments).

\begin{tabular}{ccccc}
\hline \multirow{2}{*}{ Treatment } & \multicolumn{2}{c}{ 30 Days } & \multicolumn{2}{c}{ 60 Days } \\
\cline { 2 - 5 } & $\begin{array}{c}\text { Plant Height } \\
\mathbf{( c m )}\end{array}$ & $\begin{array}{c}\text { Fresh Weight } \\
(\mathbf{g})\end{array}$ & $\begin{array}{c}\text { Plant Height } \\
(\mathbf{c m})\end{array}$ & $\begin{array}{c}\text { Fresh Weight } \\
(\mathbf{g})\end{array}$ \\
\hline ZK7+B16 & $22.33 \pm 4.04$ & $4.45 \pm 0.22$ & $56.67 \pm 5.51^{* * *}$ & $19.40 \pm 6.56$ \\
ZK7 & $18.67 \pm 5.51$ & $2.86 \pm 0.58$ & $46.00 \pm 7.55^{*}$ & $16.23 \pm 4.45$ \\
$0.5 \%$ avermectin & $18.33 \pm 4.16$ & $2.31 \pm 0.67$ & $50.00 \pm 7.944^{* *}$ & $17.59 \pm 3.12$ \\
Control & $17.00 \pm 3.00$ & $4.39 \pm 0.89$ & $33.00 \pm 2.64$ & $13.64 \pm 3.46$ \\
\hline
\end{tabular}

ZK7+B16: B. nematocida B16 fermentation broth and P. chlamydosporia ZK7 fermentation broth were evenly mixed in a ratio of 1:7 $(100 \mathrm{~mL})$; control was sterile deionized water. Data are expressed as the average of three replicates $\pm \mathrm{SD}$ (standard deviation). ${ }^{*} p<0.05,{ }^{* *} p<0.01,{ }^{* * *} p<0.001$.

\subsection{Volatiles Detected by GC/MS}

Table 7 shows the GC/MS results of B. nematocida B16 mixed with P. chlamydosporia ZK7 and P. chlamydosporia ZK7 alone after controlling for the volatiles of the blank soil samples (Figure 2). By comparing the GC/MS results of the two treatments, the levels of the volatiles furfural, 2-nonanone, hexanal, and (E)-2-hexenal increased, while that of benzaldehyde decreased.

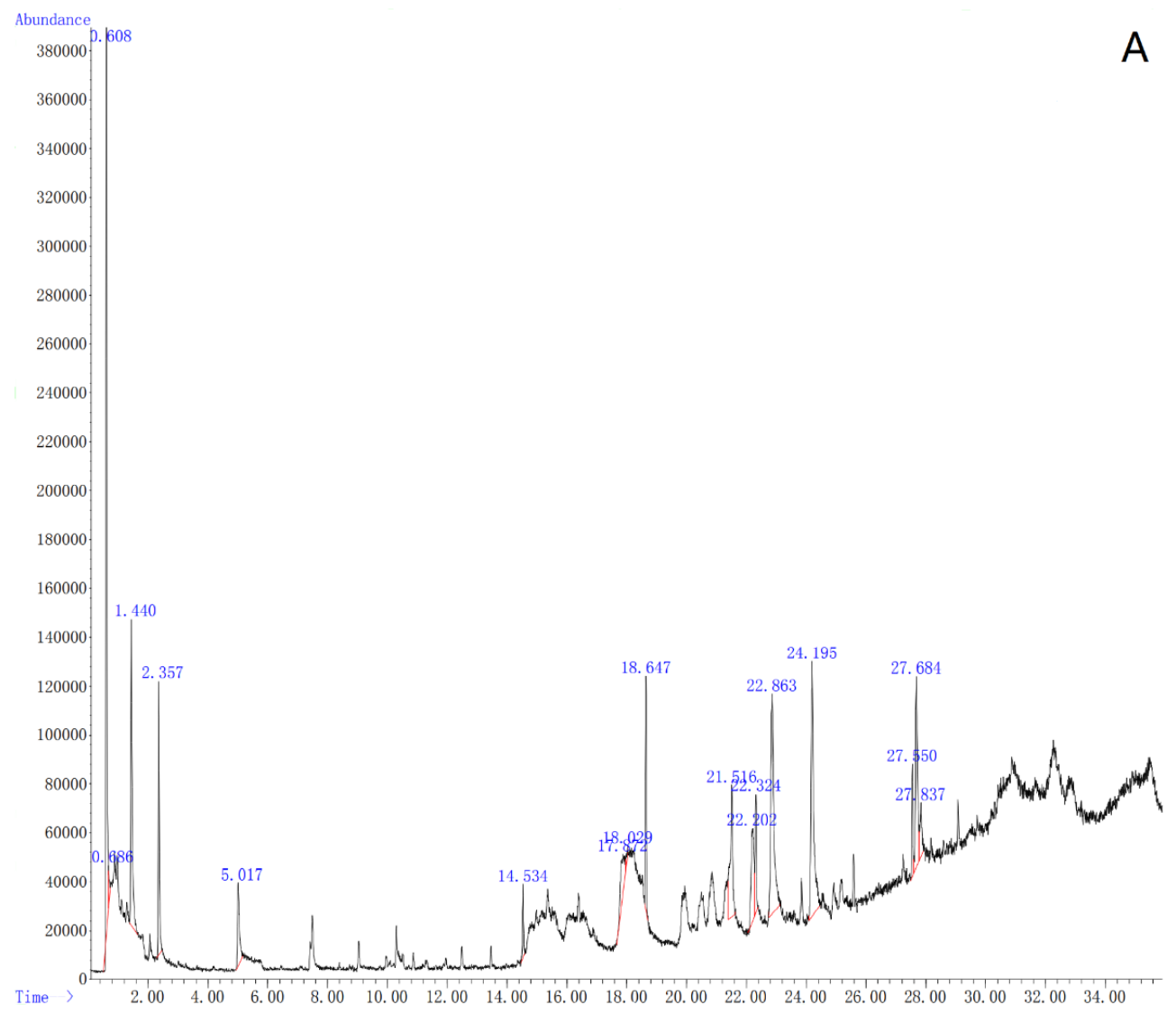

Figure 2. Cont. 


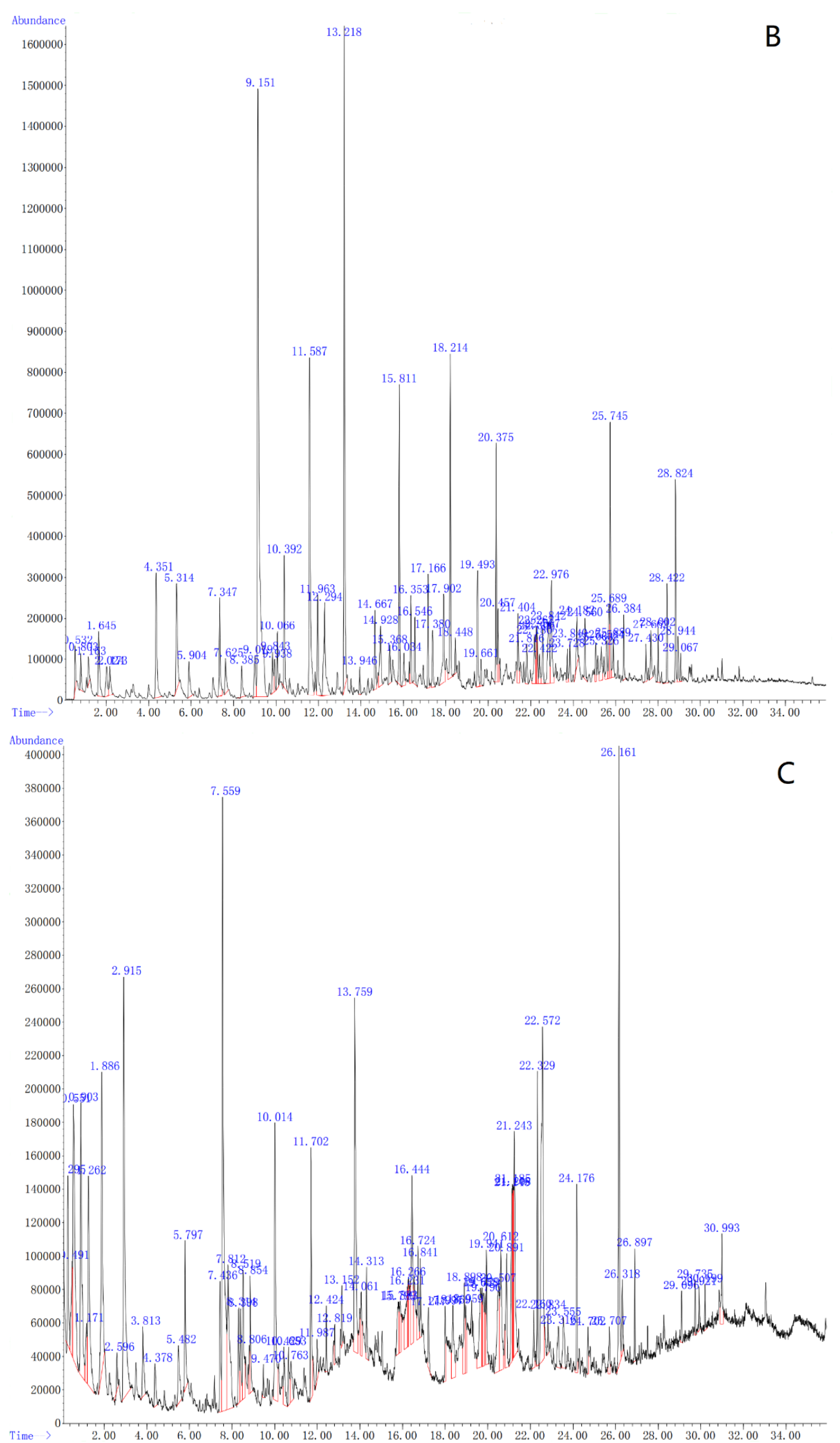

Figure 2. Volatile matters in soil. (A) Blank soil samples; (B) ZK7; (C) ZK7+B16.ZK7+B16: the supernatant of B. nematocida B16 was mixed with the spore suspension of P. chlamydosporia ZK7 in a ratio of 1:7 (total volume: $100 \mathrm{~mL}$ ). 
Table 7. Volatile matters in soil.

\begin{tabular}{cccc}
\hline & & \multicolumn{2}{c}{ Area $\%$} \\
\cline { 3 - 4 } & & B16 + ZK7 & ZK7 \\
\hline 1 & Hexanal & 11.17 & 1.91 \\
2 & (E)-2-Hexenal & 0.49 & 0.32 \\
3 & Furfural & 2.7 & 0.79 \\
4 & Benzaldehyde & 8.71 & 15.89 \\
5 & Octanal & 1.37 & 3.46 \\
6 & Benzeneacetaldehyde & 6.76 & 6.05 \\
7 & 2-Nonanone & 13.51 & 6.51 \\
8 & 2-Undecanone, & 1.47 & 2.6 \\
9 & 6,10-dimethyl- & - & 1.43 \\
10 & Furan, 2-pentyl- & - & 1.47 \\
11 & Dibenzofuran & - & 1.66 \\
\hline
\end{tabular}

Note: "-" indicates that VOCs were not detected.

\subsection{Influences of Volatiles on the Colonization of P. chlamydosporia ZK7}

The five VOCs, hexanal, furfural, (E)-2-hexenal, benzaldehyde, and 2-nonanone, promoted the colonization of $P$. chlamydosporia ZK7 in the tomato rhizosphere soil and tomato roots at 200 ppm and 400 ppm, respectively. The enhancement of P. chlamydosporia ZK7 colonization in the rhizosphere soil by the five VOCs was $906.55 \%, 252.41 \%, 1663.04 \%, 324.10 \%$, and $1300.3 \%$, respectively. The enhancement of $P$. chlamydosporia ZK7 colonization in the tomato roots was $268.07 \%, 288.66 \%, 41.18 \%, 588.24 \%$, and $155.04 \%$, respectively. At low concentrations, the five VOCs could effectively promote the colonization of P. chlamydosporia ZK7, whereas at high concentrations, they could inhibit the colonization of P. chlamydosporia ZK7 (Table 8).

Table 8. Colonization of P. chlamydosporia ZK7 in rhizosphere soil and tomato roots with volatile compounds.

\begin{tabular}{|c|c|c|c|c|c|c|}
\hline \multirow{2}{*}{ Treatment } & \multicolumn{3}{|c|}{ Biomass of ZK7 in Soil $\left(10^{3} / g\right.$ Soils $)$} & \multicolumn{3}{|c|}{ Biomass of ZK7 in Root (10 $3 / \mathrm{g}$ Soils) } \\
\hline & 200 ppm & 400 ppm & 800 ppm & 200 ppm & 400 ppm & 800 ppm \\
\hline Hexanal & $2474 \pm 40^{* * *}$ & $3812 \pm 37^{* * *}$ & $8143 \pm 43^{* * *}$ & $325 \pm 22 *$ & $876 \pm 24^{* * *}$ & $367 \pm 18^{* * *}$ \\
\hline (E)-2-Hexanal & $2500 \pm 41^{* * *}$ & $2851 \pm 29^{* * *}$ & $1109 \pm 21^{* * *}$ & $332 \pm 24 * *$ & $952 \pm 26^{* * *}$ & $670 \pm 11^{* * *}$ \\
\hline Furfural & $1746 \pm 36^{* * *}$ & $3338 \pm 32 * * *$ & $14263 \pm 176^{* * *}$ & $246 \pm 18$ & $336 \pm 23 * *$ & $341 \pm 17 * *$ \\
\hline Benzaldehyde & $1343 \pm 25^{* * *}$ & $3431 \pm 19^{* * *}$ & $603 \pm 11^{* *}$ & $257 \pm 21$ & $425 \pm 17^{* * *}$ & $1638 \pm 42^{* * *}$ \\
\hline 2-Nonanone & $1319 \pm 41^{* * *}$ & $11329 \pm 154^{* * *}$ & $7110 \pm 10^{* * *}$ & $607 \pm 27 * * *$ & $524 \pm 28^{* * *}$ & $321 \pm 19 *$ \\
\hline Fermentation broth & & $505 \pm 88^{* * *}$ & & & $1018 \pm 72^{* * *}$ & \\
\hline Control & & $809 \pm 11$ & & & $238 \pm 16$ & \\
\hline
\end{tabular}

Data are expressed as the average of three replicates $\pm \mathrm{SD}$ (standard deviation). ${ }^{*} p<0.05,{ }^{* *} p<0.01,{ }^{* * *} p<0.001$.

\section{Discussion}

The results of the field experiments showed that the biocontrol efficiency of the combination of $P$. chlamydosporia ZK7 and B. nematocida B16 was significantly higher than that of $P$. chlamydosporia ZK7 and B. nematocida B16 alone. P. chlamydosporia ZK7 is a wellstudied nematode-egg parasitic fungus. Its mycelium, conidia, and chlamydospores can survive in soil and form infestation filaments to parasitize the eggs and the females of root-knot nematodes [23]. P. chlamydosporia ZK7 degrades the nematode body wall and eggshell by producing proteases and chitinases and then kills the larvae and the eggs [24]. $B$. nematocida was found to have nematocidal activity against the nematodes Panagrellus redivivus and Bursaphelenchus xylophilus, and the mechanisms of attraction and killing were examined in Caenorhabditis elegans. B. nematocida B16 is eaten by nematodes and secretes serine protease to destroy the intestinal tract of the nematodes [25]. However, the nematocidal activity against Meloidogyne incognita may be limited by the stylet and, owing 
to the complexity and diversity of soil systems, the biocontrol effect of biocontrol fungi in the soil is greatly reduced [4].

Similarly, the addition of B. nematocida B16 increased the control effect of fungus P. chlamydosporia ZK7 and promoted plant growth. Furthermore, after bacteria were added, two important factors of $P$. chlamydosporia ZK7 that help to control nematodes, spore germination and the egg inhibition rate of $P$. chlamydosporia ZK7, were not affected. However, the colonization of fungus P. chlamydosporia ZK7 significantly increased. Bacillus M3-4 can promote the colonization of Glomus mosseae and G. versiforme around potato roots and can significantly promote the growth of potatoes [26]. An increase in the amount of colonization may be the reason for the increased control effect under the P. chlamydosporia ZK7 and B. nematocida B16 combination.

In the soil experiment, the rhizosphere colonization of P. chlamydosporia ZK7 in the tomato roots increased by $985.03 \%$ with the addition of B. nematocida B16. Rhizosphere bacteria can promote the colonization of plant roots by fungi $[27,28]$. When Pseudomonas aeruginosa was combined with P. chlamydosporia ZK7 to control the tomato root-knot nematodes, the resistance increased by more than $50 \%$, as compared to that under the use of a single agent [10]. When Fusarium oxysporum and Bacillus firmus were used in combination, their efficacy increased by $58.4 \%$ and $22.5 \%$, respectively, as compared to when used alone [29]. The inhibition rate of the root-knot nematodes was significantly improved when G. mosseae and G. versiforme were used in combination with rhizosphere growth-promoting bacteria (PGPR) [30]. However, the mechanism by which the combination of multiple bacteria improves the control effect remains unclear.

Volatile substances produced by bacteria stimulate mycelial growth and spore production [31]. Auxofuran, a new metabolite isolated from Streptomyces AcH505, promotes the growth of mycelia of Amanita muscaria at a lower concentration than other metabolites [32]. The interaction between P. chlamydosporia ZK7 and B. nematocida B16 may be related to certain signaling volatiles. Five kinds of volatile changes in tomato rhizosphere soil after the combination of B. nematocida B16 and fungus P. chlamydosporia ZK7 were studied. Further analysis and comparison of the five volatiles and the colonization percent of $P$. chlamydosporia ZK7 revealed that the changes in the contents of benzaldehyde and 2-nonanone were the main factors that resulted in an increase in the colonization percent of P. chlamydosporia ZK7 in the tomato roots. Furfural is the main volatile substance affecting the colonization of P. chlamydosporia ZK7 in the soil.

The five compounds found here have not been reported to enhance the colonization of P. chlamydosporia ZK7 or other fungi. Benzaldehyde inhibited the growth of Aspergillus fumigatus, A. terreus, A. flavus, Cryptococcus neoformans, and Candida spp. [33]. (E)-2-Hexenal inhibited the growth of many pathogenic bacteria, including Monilinia fructicola and Sclerotinia sclerotiorum [34]. Hexanal showed $100 \%$ inhibition of P. expansum and B. cinerea conidia at $4.1 \mathrm{~mol} / \mathrm{L}$. In addition, it showed significant nematode-killing activity and could significantly improve the plant height and stem diameter of tomato plants within a certain concentration range [35]. In addition, 2-nonanone also inhibited Alternaria alternata, B. cinerea, and Colletotrichum gloeosporioides mycelium growth [36]. Furfural inhibited not only the growth of the bacteria B. subtilis and P. flourescens, but also the hyphal growth of Fusarium oxysporum, F. solani, and Rhizoctonia solani. The furfural and B. subtilis combination caused a $56.94 \%$ reduction in tomato roots [37]. Furfural also effectively killed $M$. incognita [38].

In this study, after the addition of B. nematocida B16, the content of volatiles increased in the soil following an increase in the colonization amount of P. chlamydosporia ZK7 in the rhizosphere soil and tomato root, resulting in an improved biocontrol efficiency compared to P. chlamydosporia ZK7 alone. Furthermore, the increase in hexanal and furfural concentrations in the soil was beneficial not only for the colonization of P. chlamydosporia ZK7 but also for the reduction in nematode density. The combined use of B. nematocida B16 could improve the control efficiency of P. chlamydosporia ZK7 and could be used as an effective method to control root-knot nematode disease. 


\section{Conclusions}

In conclusion, our study found that the combined use of B. nematocida B16 and P. chlamydosporia ZK7 caused volatile ranges that resulted in increased colonization of biocontrol fungi and improved biocontrol efficiency against nematodes. The determination of signal substances by gas chromatography showed that benzaldehyde and 2-nonanone were the main factors that resulted in an increase in the colonization of fungi P. chlamydosporia ZK7 in the tomato roots. Furfural was the main volatile substance that affected the colonization of P. chlamydosporia ZK7 in the soil. This combined model could be used to promote the ability of biocontrol fungi to control root-knot nematodes.

Author Contributions: All authors contributed to the study and conducted experiments. C.K. carried out the main experiments and data collection. S.Z. participated in the pot experiment. T.B. analyzed data and wrote a manuscript draft. M.M. guided experimental design. Y.L. participated in experimental design and revised the manuscript. All authors have read and agreed to the published version of the manuscript.

Funding: This work was funded by the National Natural Science Foundation Program of China (31860027 and 31960022) and a grant from the Ten-Thousand Talents Program in Yunnan Province (YNWR-CYJS-2019-042).

Institutional Review Board Statement: Not applicable.

Informed Consent Statement: Not applicable.

Data Availability Statement: Not applicable.

Conflicts of Interest: The authors declare no conflict of interest.

\section{References}

1. Coyne, D.L.; Laura, C.; Dalzell, J.J.; Claudius-Cole, A.O.; Solveig, H.; Nessie, L. Plant-parasitic nematodes and food security in sub-saharan Africa. Annu. Rev. Phytopathol. 2018, 56, 381-403. [CrossRef]

2. Pandey, R.; Kalra, A.; Tandon, S.; Mehrotra, N.; Singh, H.N.; Kumar, S. Essential oils as potent sources of nematidical compounds. J. Phytopathol. 2010, 148, 501-502. [CrossRef]

3. Ntalli, N.G.; Pierluigi, C. Botanical nematicides: A review. J. Agric. Food. Chem. 2012, 60, 9929-9940. [CrossRef] [PubMed]

4. Kerry, B.R.; Grump, D.H. Observation on fungal parasites of females and eggs of the cereal cyst-nematodes, Heterodera avenae, and other cyst nematodes. Nematological 2011, 23, 193-201.

5. Stirling, G.R.; Licastro, K.A.; West, L.M.; Smith, L.J. Development of commercially acceptable formulations of the nematoph-agous fungus Verticillium chlamydosporium. Biol. Control 1998, 11, 217-223. [CrossRef]

6. Zhang, Y.; Li, G.H.; Zhang, K.Q. Research overview of nematode fungi resources. Acta Mycol. Sin. 2011, 30, 836-845.

7. Syed-Ab-Rahman, S.F.; Carvalhais, L.C.; Chua, E.T.; Chung, F.Y.; Moyle, P.M.; Eltanahy, E.; Schenk, P.M. Soil bacterial diffusible and volatile organic compounds inhibit Phytophthora capsici and promote plant growth. Sci. Total Environ. 2019, 692, 267-280. [CrossRef]

8. Song, G.C.; Ryu, C.-M. Evidence for Volatile Memory in Plants: Boosting Defence Priming through the Recurrent Application of Plant Volatiles. Mol. Cells 2018, 41, 724-732. [CrossRef] [PubMed]

9. Kerry, B.R.; Hirsch, P.R. Ecology of Pochonia chlamydosporia in the Rhizosphere at the Population, Whole Organism and Molecular Scales. In Biological Control of Plant-Parasitic Nematodes; Springer: Berlin/Heidelberg, Germany, 2011; pp. 171-182. [CrossRef]

10. Siddiqui, I.A.; Shaukat, S.S. Combination of Pseudomonas aeruginosa and Pochonia chlamydosporia for Control of Root-Infecting Fungi in Tomato. J. Phytopathol. 2003, 151, 215-222. [CrossRef]

11. Wheatley, R.E. The consequences of volatile organic compound mediated bacterial and fungal interactions. Antonie Van Leeuwenhoek 2002, 81, 357-364. [CrossRef] [PubMed]

12. Cao, X.; Zhang, R.; Meng, S.; Ren, Q.; Mo, M.; Liu, Y. Biocontrol potential of Agromyces allii 130935 and its metabolites against root-knot nematode Meloidogyne incognita. Rhizosphere 2021, 19, 100378. [CrossRef]

13. Gao, H.; Qi, G.; Yin, R.; Zhang, H.; Li, C.; Zhao, X. Bacillus cereus strain S2 shows high nematicidal activity against Meloidogyne incognita by producing sphingosine. Sci. Rep. 2016, 6, 28756. [CrossRef] [PubMed]

14. Zhou, Y.Y.; Chen, J.S.; Zhu, X.F.; Wang, Y.Y.; Chen, L.J. Efficacy of Bacillus megaterium strain Sneb207 against soybean cyst nematode (Heterodera glycines) in soybean. Pest Manag. Sci. 2021, 77, 568-576. [CrossRef]

15. Nguyen, L.; Jang, J.Y.; Kim, T.Y.; Yu, N.H.; Kim, J.C. Nematicidal activity of verrucarin A and roridin A isolated from My-rothecium verrucaria against Meloidogyne incognita. Pestic. Biochem. Physiol. 2018, 148, 133-143. [CrossRef] [PubMed] 
16. Ruanpanun, P.; Nimnoi, P. Evaluation on the efficiency and persistence of Streptomyces jietaisiensis strain A034 in controlling root knot disease and promoting plant growth in the plant-parasitic nematode infested soils. Biol. Control 2020, $144,104221$. [CrossRef]

17. Pfeiffer, I. Communication among Soil Bacteria and Fungi. Plant Soil 2010, 23, 427-437. [CrossRef]

18. Li, Q.; Ning, P.; Zheng, L.; Huang, J.; Li, G.; Hsiang, T. Fumigant activity of volatiles of Streptomyces globisporus JK-1 against Penicillium italicum on Citrus microcarpa. Postharvest Biol. Technol. 2010, 58, 157-165. [CrossRef]

19. Li, Q.; Ning, P.; Zheng, L.; Huang, J.; Li, G.; Hsiang, T. Effects of volatile substances of Streptomyces globisporus JK-1 on control of Botrytis cinerea on tomato fruit. Biol. Control 2012, 61, 113-120. [CrossRef]

20. Hassan, Z.; Thani, R.; Alnaimi, H.; Migheli, Q.; Jaoua, S. Investigation and application of Bacillus licheniformis volatile compounds for the biological control of toxigenic Aspergillus and Penicillium spp. ACS Omega 2019, 4, 17186-17193. [CrossRef]

21. Stirling, G.R.; White, A.M. Distribution of a parasite of root-knot nematodes in south Australian vineyards. Plant Dis. 1982, 66, 52-53. [CrossRef]

22. Manzanilla, R.H.; Clark, I.M.; Atkins, S.D.; Hirsch, P.R.; Kerry, B.R. Rapid and reliable DNA extraction and PCR fingerprinting methods to discriminate multiple biotypes of the nematophagous fungus Pochonia chlamydosporia isolated. Appl. Microbiol. 2007, 48, 71-76. [CrossRef]

23. Maciá-Vicente, J.G.; Jansson, H.; Talbot, N.J.; Lopez-Llorca, L.V. Real-time pcr quantification and live-cell imaging of endo-phytic colonization of barley (hordeum vulgare) roots by Fusarium equiseti and Pochonia chlamydosporia. New Phytol. 2009, 182, 213-228. [CrossRef]

24. Stirling, G.R. Biological Control of Plant Parasitic Nematodes: Progress, Problems and Prospects; CABI: Wallingford, UK, 1993; Volume 8, p. 106.

25. Zaki, A.S.; Irshad, M. Biological control of plant parasitic nemotodes by fungi. Bioresour. Technol. 1996, 58, $229-239$.

26. Niu, Q.H. Novel Mechanisms on Alluring and Killing Nematodes by Pathogenic Bacteria Bacillus Nematocida B16; Yunnan University: Kunming, China, 2009.

27. Tan, S.P.; Sun, W.W.; Liu, R.J. Synergistic effect of fungi of the Glomeromycota and Bacillus M3-4 on the reduction of potato bacterial wilt and its mechanism. Plant Pathol. 2015, 45, 661-669.

28. Sheng, J.M.; Wu, X.Q. Study on the Interaction between Mycorrhizal Fungi and Plant Rhizosphere Microorganisms. J. For. Res. 2007, 22, 104-108.

29. Mendoza, A.R.; Sikora, R.A. Biological control of Radopholus similis in banana by combined application of the mutualistic endophyte Fusarium oxysporum strain 162, the egg pathogen Paecilomyces lilacinus strain 251 and the antagonistic bacteria Bacillus firmus. BioControl 2008, 54, 263-272. [CrossRef]

30. Liu, R.J.; Dai, X.Z. Suppression of the root-knot nematode [Meloidogyne incognita (kofoid \& white) chitwood] on tomato by dual inoculation with arbuscular mycorrhizal fungi and plant growth-promoting rhizobacteria. Mycorrhiza 2012, 22, 289-296.

31. Miransari, M. Interactions between arbuscular mycorrhizal fungi and soil bacteria. Appl. Microbiol. Biotechnol. 2010, 89, 917-930. [CrossRef]

32. Song, R.Q.; Deng, X.; Song, X.S. Progress of researches on interaction mechanism between Ectomycorrhiza fungi and Mycor-rhizal Helper bacteria. J. Jilin Agric. Univ. 2016, 38, 379-384.

33. Kim, J.H.; Chan, K.L.; Mahoney, N.; Campbell, B.C. Antifungal activity of redox-active benzaldehydes that target cellular antioxidation. Ann. Clin. Microbiol. Antimicrob. 2011, 10, 23. [CrossRef]

34. Song, J.; Hildebrand, P.D.; Fan, L.; Forney, C.F.; Renderos, W.E.; Campbell-Palmer, L.; Doucette, C. Effect of Hexanal Vapor on the Growth of Postharvest Pathogens and Fruit Decay. J. Food Sci. 2007, 72, M108-M112. [CrossRef] [PubMed]

35. Song, J.; Fan, L.; Forney, C.; Campbell-Palmer, L.; Fillmore, S. Effect of hexanal vapor to control postharvest decay and extend shelf-life of highbush blueberry fruit during controlled atmosphere storage. Can. J. Plant Sci. 2010, 90, 359-366. [CrossRef]

36. Liu, W.-W.; Mu, W.; Zhu, B.-Y.; DU, Y.-C.; Liu, F. Antagonistic Activities of Volatiles from Four Strains of Bacillus spp and Paenibacillus spp. Against Soil-Borne Plant Pathogens. Agric. Sci. China 2008, 7, 1104-1114. [CrossRef]

37. Nehal, S.E.; Nadia, G. Furfural approaches as control measures aginst root rot and root-knot incidence of tamato under greenhouse and field conditions. J. Plant Prot. Res. 2008, 48, 93-105.

38. Cabrera, J.A.; Wang, D.; Gerik, J.S.; Gan, J. Spot drip application of dimethyl disulfide as a post-plant treatment for the control of plant parasitic nematodes and soilborne pathogens in grape production. Pest Manag. Sci. 2013, 70, 1151-1157. [CrossRef] [PubMed] 